\title{
Synthesis and Antibacterial Evaluation of 3,5-Diaryl-1,2,4-oxadiazole Derivatives
}

\author{
Felipe S. Cunha, ${ }^{a}$ Joseli M. R. Nogueira ${ }^{b}$ and Alcino P. de Aguiar ${ }^{*, a}$ \\ ${ }^{a}$ Laboratório de Síntese Orgânica, Seção de Engenharia Química, Instituto Militar de Engenharia, \\ Praça General Tibúrcio, 80, Praia Vermelha, Urca, 22290-270 Rio de Janeiro-RJ, Brazil \\ ${ }^{b}$ Escola Nacional de Saúde Pública (ENSP), Fundação Oswaldo Cruz (Fiocruz), \\ Rua Leopoldo Bulhões, 1480, Manguinhos, 21041-210 Rio de Janeiro-RJ, Brazil
}

\begin{abstract}
This manuscript reports the synthesis of twenty 3,5-diaryl-1,2,4-oxadiazole derivatives, nine of which are novel compounds. The amidoxime reaction with acyl chlorides obtained from substituted benzoic acids was used. All compounds were tested against five standard (American Type Culture Collection (ATCC)) bacteria: Escherichia coli, Pseudomonas aeruginosa, Enterococcus faecalis, Proteus mirabilis and Staphylococcus aureus. Screening assays were carried out using agardiffusion technique, in which $100 \mu \mathrm{M}$ heterocyclic compounds solutions (20\% dimethylsulfoxide/ water) were employed. The minimum inhibitory concentrations (MIC) of the active compounds were determined by serial dilutions at decreasing concentrations in microtiter plates. The nitrated derivatives gave the best test results, where MIC $=60 \mu \mathrm{M}($ E. coli $)$ was the lowest value found for an ortho-nitrated derivative. The activity of these compounds possibly involves a mechanism via free radicals. $S$. aureus and $P$. aeruginosa were resistant to all compounds.
\end{abstract}

Keywords: oxadiazole, amidoxime, cyclization, nitrocompound, antibacterial

\section{Introduction}

The increasing bacterial resistance to known antibiotics has been causing concern in the population, since their therapeutic possibilities have been diminishing. ${ }^{1}$ This has led to intensified research involving the synthesis and evaluation of heterocyclic derivatives with antimicrobial properties, such as 1,2,4-oxadiazoles. ${ }^{2}$

The indiscriminate use of antibiotics is pointed out as one of the main causes for the development of bacterial resistance. The growth of bacterial resistance has caused the mortality of an expressive number of people worldwide. Even the main commercial antimicrobial compounds (e.g., ampicillin, posaconazole, ciprofloxacin) may have limited action, nowadays, against strains of resistant microorganisms. ${ }^{3}$ Therefore, there is an urgent need to find new molecules with more efficient

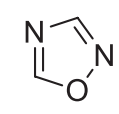<smiles>c1cnon1</smiles>

1,2,4-oxadiazol

1,2,5-oxadiazol antibacterial properties, as well as simplified synthetic routes. The oxadiazole nucleus presents four isomers (Figure 1); however, one of them, the 1,2,3-oxadiazole isomer, is not of any practical use, as it is unstable and decomposes easily. ${ }^{4}$

Although the 1,2,4-oxadiazole heterocycle was first synthesized in $1884,{ }^{5}$ it was only in the 1990 s that this nucleus aroused interest within the scientific community. ${ }^{6}$ The literature reports a diverse set of applications for the 1,2,4-oxadiazole core in medicinal chemistry, ${ }^{7,8}$ such as antiasthmatic, ${ }^{9}$ antidiabetic, ${ }^{10}$ antitumoral, ${ }^{11}$ anti-inflammatory, ${ }^{12}$ antioxidant, ${ }^{12}$ and antimicrobial. ${ }^{13}$ Different parameters are used to quantify these biological activities, such as half maximal inhibitory concentration $\left(\mathrm{IC}_{50}\right)$, half maximal effective concentration $\left(\mathrm{EC}_{50}\right)$ or minimum inhibition concentration (MIC) (Figure 2). In Materials Science, structures containing this heterocycle<smiles>c1nnco1</smiles><smiles>c1conn1</smiles>

1,3,4-oxadiazol

1,2,3-oxadiazol

Figure 1. Isomers of oxadiazoles.

*e-mail: alcino@ime.eb.br 


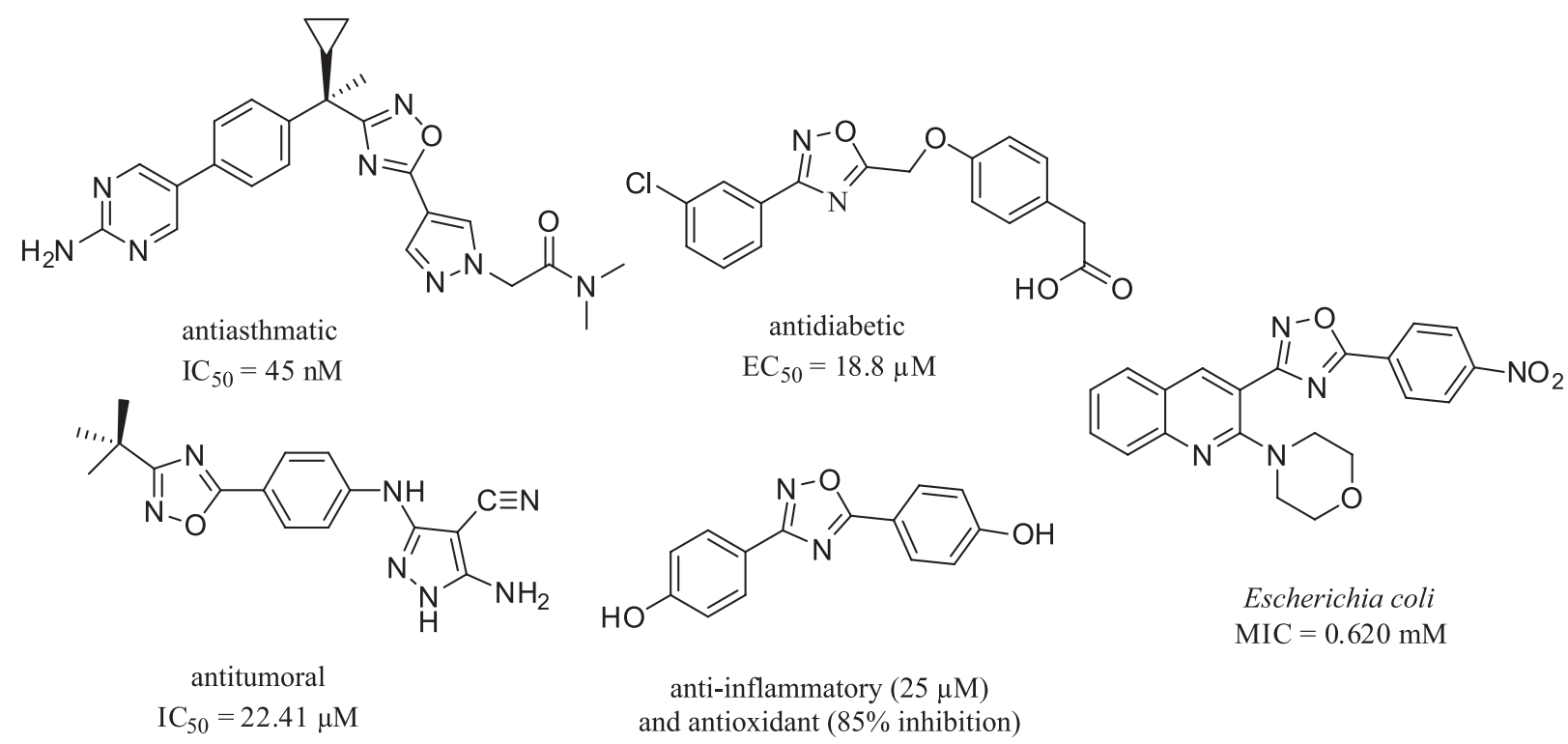

Figure 2. Examples of bioactive 1,2,4-oxadiazoles.

have technological applications in ionic liquids and liquid crystals, for example. ${ }^{14-16}$

The 1,2,4-oxadiazole derivatives can be synthesized via two classical methods: 1,3-dipolar cycloaddition of nitrile oxides to the nitrile functional group ${ }^{17}$ and the cyclization of amidoxime derivatives, ${ }^{18}$ the latter being the most common.

This paper reports the synthesis of 3,5-diphenyl1,2,4-oxadiazoles and 3-pyridino-5-phenyl1,2,4-oxadiazole derivatives employing the amidoxime route. These products have different substitution patterns (position or nature of the substituents). All compounds had their antibacterial properties evaluated against five bacteria (Gram-positive and Gram-negative).

\section{Experimental}

\section{Materials and methods}

All reagents and solvents were purchased (Aldrich, Brazil) and used without further purification. All reactions, except the synthesis of the amidoximes, were performed in a closed system to protect against moisture. The reactions were monitored by thin layer chromatography (TLC) using pre-coated silica gel 60 F254 plates (Merck, Brazil). Visualization of the plates was accomplished by using UV light. Infrared spectra (IR) were obtained on a PerkinElmer Spectrum 100 (USA) spectrometer. ${ }^{1} \mathrm{H}$ and ${ }^{13} \mathrm{C}$ nuclear magnetic resonance (NMR) spectra were obtained on a Bruker AVANCE DPX 400 (USA) spectrometer. Chemical shifts $(\delta)$ are reported in ppm relative to tetramethylsilane. The solvent used was $\mathrm{CDCl}_{3}$ and dimethylsulfoxide- $d_{6}$ (DMSO- $d_{6}$ ) and the coupling constant $(J)$ is given in hertz $(\mathrm{Hz})$. Multiplicities were presented as singlet (s), doublet (d), triplet (t), quadruplet (q) and multiplet (m). Melting points were determined in open capillary tubes (Gehaka PF 1000, Brazil) and are uncorrected. A gas chromatograph, Agilent 7890A (USA), coupled to a nitrogen and phosphorus detector (NPD) and a mass spectrometer, Agilent MSD 5975C (USA) were used.

\section{Synthesis of amidoximes (1-4)}

Solutions of $50 \mathrm{mmol}$ of hydroxylamine hydrochloride, $25 \mathrm{mmol}$ of anhydrous sodium carbonate and $20 \mathrm{~mL}$ of water were added to a round-bottomed flask. The mixture was homogenized until no effervescence occurred. Then, $33 \mathrm{mmol}$ of a nitrile derivative (1-4) and $20 \mathrm{~mL}$ of ethanol were added to the reaction medium, which was kept under stirring and refluxed for $5 \mathrm{~h}$. After this period, the product, an amidoxime (5-8), was recrystallized from water (Scheme 1). ${ }^{19}$

Synthesis of acyl chloride (9-19)

Thionyl chloride ( $5 \mathrm{~mL}$ ) was slowly added to a roundbottomed flask containing carboxylic acid $(3.1 \mathrm{mmol})$. The medium was refluxed for $2 \mathrm{~h}$. Only acyl chloride (9-19) remained in the flask after the excess thionyl chloride was removed by distillation. ${ }^{20}$

\section{Synthesis of the 1,2,4-oxadiazol derivatives (20-39)}

The newly synthesized acyl chloride dissolved in toluene $(10 \mathrm{~mL})$ was slowly added to a solution of 

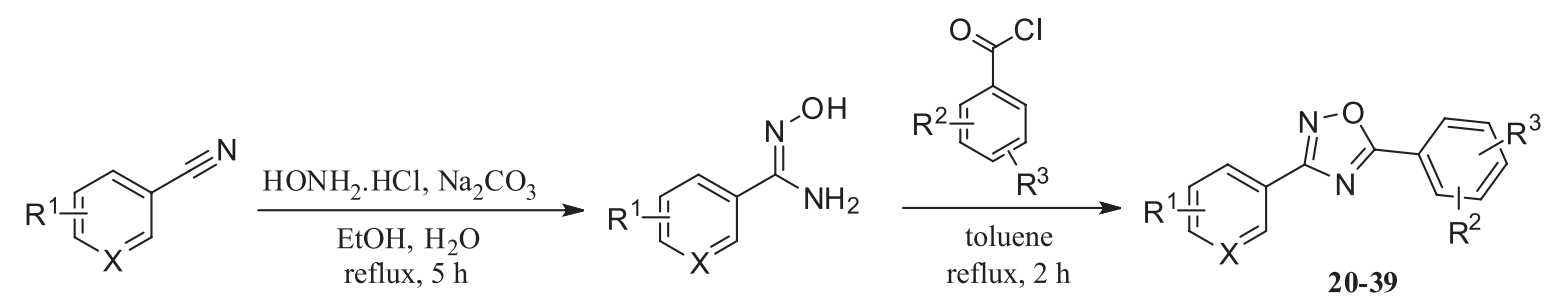

$$
\begin{aligned}
& \mathbf{1}-\left(X=R^{1}=H\right) \\
& \mathbf{2}-\left(X=C ; R^{1}=2-C l\right) \\
& \mathbf{3}-\left(X=C ; R^{1}=3-C l\right) \\
& 4-\left(X=N ; R^{1}=H\right)
\end{aligned}
$$

$$
\begin{aligned}
& 9-\left(\mathrm{R}^{2}=\mathrm{H} ; \mathrm{R}^{3}=\mathrm{H}\right) \\
& 10-\left(\mathrm{R}^{2}=2-\mathrm{NO}_{2} ; \mathrm{R}^{3}=\mathrm{H}\right) \\
& 11-\left(\mathrm{R}^{2}=2 \mathrm{Cl} ; \mathrm{R}^{3}=\mathrm{H}\right) \\
& 12-\left(\mathrm{R}^{2}=3-\mathrm{Br} ; \mathrm{R}^{3}=\mathrm{H}\right) \\
& 13-\left(\mathrm{R}^{2}=2-\mathrm{Cl} ; \mathrm{R}^{3}=5-\mathrm{NO}_{2}\right) \\
& 14-\left(\mathrm{R}^{2}=2-\mathrm{Br}^{3}=\mathrm{R} \mathrm{R}^{3}\right) \\
& 15-\left(\mathrm{R}^{2}=3-\mathrm{NO}_{2} ; \mathrm{R}^{3}=\mathrm{H}\right) \\
& 16-\left(\mathrm{R}^{2}=2-\mathrm{I} ; \mathrm{R}^{3}=\mathrm{H}\right) \\
& 17-\left(\mathrm{R}^{2}=3-\mathrm{NO}_{2} ; \mathrm{R}^{3}=5-\mathrm{NO}_{2}\right) \\
& 18-\left(\mathrm{R}^{2}=4-\mathrm{NO}_{2} ; \mathrm{R}^{3}=\mathrm{H}\right) \\
& 19-\left(\mathrm{R}^{2}=2-\mathrm{OH} ; \mathrm{R}^{3}=\mathrm{H}\right)
\end{aligned}
$$

Scheme 1. Synthetic route of the 1,2,4-oxadiazol derivatives.

amidoxime $(2.5 \mathrm{mmol})$ dissolved in toluene $(40 \mathrm{~mL})$ in a $250 \mathrm{~mL}$ round-bottomed flask at $25^{\circ} \mathrm{C}$ and under constant stirring. After the addition, the solution was refluxed for $20 \mathrm{~h}$, and then washed with sodium carbonate solution. The organic phase was dried with anhydrous sodium sulfate and thereafter the toluene was removed under vacuum by heating. A solid was obtained, which was purified by flash column chromatography using a hexane/ethyl acetate mixture as eluent with an increasing polarity gradient (9:1 to $6: 4) .{ }^{20}$

\section{3-Phenyl-5-phenyl-1,2,4-oxadiazole (20)}

Yield: 76\%; mp 108-110 ${ }^{\circ} \mathrm{C}$; ${ }^{1} \mathrm{H}$ NMR $(600.00 \mathrm{MHz}$, $\left.\mathrm{CDCl}_{3}\right) \delta 8.80(\mathrm{~d}, 2 \mathrm{H}, J 7.8 \mathrm{~Hz}), 8.76(\mathrm{~d}, 2 \mathrm{H}, J 6.0 \mathrm{~Hz})$, $8.18(\mathrm{t}, 1 \mathrm{H}, J 7.8 \mathrm{~Hz}), 8.13(\mathrm{t}, 2 \mathrm{H}, J 7.8 \mathrm{~Hz}), 8.10(\mathrm{~d}, 3 \mathrm{H}$, $J 6.0 \mathrm{~Hz}) ;{ }^{13} \mathrm{C} \mathrm{NMR}\left(150.0 \mathrm{MHz}, \mathrm{CDCl}_{3}\right) \delta 175.7,168.9$, 132.7, 131.2, 129.1, 128.8, 128.1, 127.5, 126.9, 124.3; IR $(\mathrm{KBr}) \mathrm{v} / \mathrm{cm}^{-1} 1612,1600-1390,735,695$; high resolution mass spectrometry (HRMS) (electrospray ionization (ESI)) $m / z$, calcd. for $\mathrm{C}_{14} \mathrm{H}_{10} \mathrm{~N}_{2} \mathrm{O}[\mathrm{M}+\mathrm{H}]^{+}: 223.0865$, found: 223.0867 .

\section{3-(4-Chlorophenyl)-5-phenyl-1,2,4-oxadiazole (21)}

Yield: 68\%; mp 111-113 ${ }^{\circ} \mathrm{C}$; ${ }^{1} \mathrm{H}$ NMR $(400.00 \mathrm{MHz}$, $\left.\mathrm{CDCl}_{3}\right) \delta 8.20(\mathrm{~d}, 2 \mathrm{H}, J 8.0 \mathrm{~Hz}), 8.11(\mathrm{~d}, 2 \mathrm{H}, J 8.0 \mathrm{~Hz})$, $7.61(\mathrm{t}, 1 \mathrm{H}, J 8.0 \mathrm{~Hz}), 7.55(\mathrm{t}, 2 \mathrm{H}, J 8.0 \mathrm{~Hz}), 7.48(\mathrm{~d}, 2 \mathrm{H}$, $J 8.0 \mathrm{~Hz}) ;{ }^{13} \mathrm{C}$ NMR $\left(100.0 \mathrm{MHz}, \mathrm{CDCl}_{3}\right) \delta 175.9,168.2$, 137.3, 132.9, 129.2, 129.1, 128.8, 128.2, 125.5, 124.1; IR $(\mathrm{KBr}) \mathrm{v} / \mathrm{cm}^{-1} 1604,1550,1489,1404,1037,840,740$, 695; HRMS (ESI) $\mathrm{m} / z$, calcd. for $\mathrm{C}_{14} \mathrm{H}_{9} \mathrm{ClN}_{2} \mathrm{O}[\mathrm{M}+\mathrm{H}]^{+}$: 257.0476, found: 257.0480 .
3-(4-Chlorophenyl)-5-(2-chlorophenyl)-1,2,4-oxadiazole (22)

Yield: $49 \%$; mp 128-130 ${ }^{\circ} \mathrm{C}$; ${ }^{1} \mathrm{H}$ NMR $(400.00 \mathrm{MHz}$, $\left.\mathrm{CDCl}_{3}\right) \delta 8.15(\mathrm{dd}, 1 \mathrm{H}, J 6.0,1.6 \mathrm{~Hz}), 8.12(\mathrm{~d}, 2 \mathrm{H}$, $J 8.0 \mathrm{~Hz}), 7.60(\mathrm{dd}, 1 \mathrm{H}, J 8.0,1.2 \mathrm{~Hz}), 7.52(\mathrm{td}, 1 \mathrm{H}, J 7.6$, $1.2 \mathrm{~Hz}), 7.49$ (d, 2H, J 8.0 Hz), 7.44 (td, 1H, J 7.6, 1.2 Hz); ${ }^{13} \mathrm{CNMR}\left(100.0 \mathrm{MHz}, \mathrm{CDCl}_{3}\right) \delta 174.5,167.9,137.4,133.9$, 133.2, 131.9, 131.5, 129.2, 128.9, 127.1, 125.3, 123.5; IR (KBr) v / $\mathrm{cm}^{-1} 1597,1543,1411,1357,1087,833$, 740; HRMS (ESI) $m / z$, calcd. for $\mathrm{C}_{14} \mathrm{H}_{8} \mathrm{Cl}_{2} \mathrm{~N}_{2} \mathrm{O}[\mathrm{M}+\mathrm{H}]^{+}$: 291.0086, found: 291.0082 .

3-(4-Chlorophenyl)-5-(2-bromophenyl)-1,2,4-oxadiazole (23)

Yield: 45\%; mp 130-134 ${ }^{\circ} \mathrm{C} ;{ }^{1} \mathrm{H}$ NMR $(400.00 \mathrm{MHz}$, $\left.\mathrm{CDCl}_{3}\right) \delta 8.14(\mathrm{~d}, 2 \mathrm{H}, J 8.8 \mathrm{~Hz}), 8.08(\mathrm{dd}, 1 \mathrm{H}, J 7.6,2.0 \mathrm{~Hz})$, 7.80 (dd, 1H, J 7.6, 1.2 Hz), 7.50 (t, 1H, J $6.4 \mathrm{~Hz}$ ), 7.48 $(\mathrm{d}, 2 \mathrm{H}, J 8.4 \mathrm{~Hz}), 7.44(\mathrm{td}, 1 \mathrm{H}, J 7.6,2.0 \mathrm{~Hz}) ;{ }^{13} \mathrm{C} \mathrm{NMR}$ $\left(100.0 \mathrm{MHz}, \mathrm{CDCl}_{3}\right) \delta 175.0,167.9,137.5,134.9,133.2$, 132.1, 129.2, 128.9, 127.6, 125.6, 125.3, 122.2; IR (KBr) $v / \mathrm{cm}^{-1} 1589,1535,1411,910,833,740$; HRMS (ESI) $m / z$, calcd. for $\mathrm{C}_{14} \mathrm{H}_{8} \mathrm{BrClN}_{2} \mathrm{O}[\mathrm{M}+\mathrm{H}]^{+}: 334.9576$, found: 334.9581 .

3-(4-Chlorophenyl)-5-(2-iodophenyl)-1,2,4-oxadiazole (24)

Yield: 48\%; mp 91-93 ${ }^{\circ} \mathrm{C}$; ${ }^{1} \mathrm{H}$ NMR (400.00 MHz, $\left.\mathrm{CDCl}_{3}\right) \delta 8.12(\mathrm{~d}, 2 \mathrm{H}, J 8.8 \mathrm{~Hz}), 8.10(\mathrm{dd}, 1 \mathrm{H}, J 0.8 \mathrm{~Hz})$, $8.00(\mathrm{dd}, 1 \mathrm{H}, J 8.0,1.6 \mathrm{~Hz}), 7.53(\mathrm{td}, 1 \mathrm{H}, J 7.6,0.8 \mathrm{~Hz}$ ), $7.50(\mathrm{~d}, 2 \mathrm{H}, J 8.8 \mathrm{~Hz}), 7.25$ (td, $1 \mathrm{H}, J 8.0,1.6 \mathrm{~Hz}) ;{ }^{13} \mathrm{C} \mathrm{NMR}$ $\left(100.0 \mathrm{MHz}, \mathrm{CDCl}_{3}\right) \delta 175.6,167.8,141.8,137.5,133.1$, 131.7, 129.2, 129.2, 128.9, 128.3, 125.3, 94.5; IR (KBr) 
$V / \mathrm{cm}^{-1} 1581,1535,1404,1357,1087,833,740$; HRMS (ESI) $m / z$, calcd. for $\mathrm{C}_{14} \mathrm{H}_{8} \mathrm{ClIN}_{2} \mathrm{O}[\mathrm{M}+\mathrm{H}]^{+}: 382.9443$, found: 382.9435 .

3-(4-Chlorophenyl)-5-(3-bromophenyl)-1,2,4-oxadiazole (25)

Yield: 47\%; mp 159-161 ${ }^{\circ} \mathrm{C} ;{ }^{1} \mathrm{H}$ NMR (400.00 MHz, $\left.\mathrm{CDCl}_{3}\right) \delta 8.35(\mathrm{~s}, 1 \mathrm{H}), 8.13(\mathrm{~d}, 1 \mathrm{H}, J 8.0 \mathrm{~Hz}), 8.11(\mathrm{~d}, 2 \mathrm{H}$, $J 8.0 \mathrm{~Hz}), 7.75$ (d, 1H, J 8.0 Hz), 7.49 (d, 2H, J 8.0 Hz), $7.43(\mathrm{t}, 1 \mathrm{H}, J 8.0 \mathrm{~Hz}) ;{ }^{13} \mathrm{C} \mathrm{NMR}\left(100.0 \mathrm{MHz}, \mathrm{CDCl}_{3}\right)$ $\delta$ 174.5, 168.3, 137.5, 135.8, 131.0, 130.7, 129.2, 128.8, 126.6, 125.9, 125.2, 123.2; IR (KBr) v / cm $\mathrm{cm}^{-1} 1597,1550$, 1473, 1404, 1357, 840, 748, 671; HRMS (ESI) $\mathrm{m} / \mathrm{z}$, calcd. for $\mathrm{C}_{14} \mathrm{H}_{8} \mathrm{BrClN}_{2} \mathrm{O}[\mathrm{M}+\mathrm{H}]^{+}:$334.9509, found: 334.9512 .

3-(4-Chlorophenyl)-5-(2-nitrophenyl)-1,2,4-oxadiazole (26)

Yield: 51\%; mp 137-139 ${ }^{\circ} \mathrm{C}$; ${ }^{1} \mathrm{H}$ NMR (400.00 MHz, $\left.\mathrm{CDCl}_{3}\right) \delta 8.08(\mathrm{~d}, 2 \mathrm{H}, J 8.0 \mathrm{~Hz}), 8.03(\mathrm{~m}), 7.80(\mathrm{~m}), 7.48$ $(\mathrm{d}, 2 \mathrm{H}, J 8.0 \mathrm{~Hz}) ;{ }^{13} \mathrm{C} \mathrm{NMR}\left(100.0 \mathrm{MHz}, \mathrm{CDCl}_{3}\right) \delta 172.6$, 168.2 , 148.8, 137.7, 133.2, 132.9, 131.4, 129.3, 128.9, 124.8, 124.7, 118.9; IR (KBr) v / $\mathrm{cm}^{-1} 1555,1527,1481$, 1404, 1350, 1095, 840, 740; HRMS (ESI) $\mathrm{m} / z$, calcd. for $\mathrm{C}_{14} \mathrm{H}_{8} \mathrm{ClN}_{3} \mathrm{O}_{3}[\mathrm{M}+\mathrm{H}]^{+}:$302.0326, found: 302.0327 .

3-(4-Chlorophenyl)-5-(3-nitrophenyl)-1,2,4-oxadiazole (27)

Yield: 45\%; mp 168-170 ${ }^{\circ} \mathrm{C}$; ${ }^{1} \mathrm{H}$ NMR (400.00 MHz, $\left.\mathrm{CDCl}_{3}\right) \delta 9.06(\mathrm{~s}, 1 \mathrm{H}), 8.53(\mathrm{~d}, 1 \mathrm{H}, J 7.6 \mathrm{~Hz}), 8.48(\mathrm{~d}, 1 \mathrm{H}$, $J 7.6 \mathrm{~Hz}), 8.13(\mathrm{~d}, 2 \mathrm{H}, J 8.8 \mathrm{~Hz}), 7.79(\mathrm{t}, 1 \mathrm{H}, J 8.0 \mathrm{~Hz}), 7.51$ (d, 2H, J 8.4 Hz); ${ }^{13} \mathrm{C}$ NMR (100.0 MHz, $\left.\mathrm{CDCl}_{3}\right) \delta 173.7$, $168.5,148.7,137.8,133.5,130.5,129.3,128.9,127.2$, 125.7, 124.8, 123.2; IR (KBr) v / cm ${ }^{-1} 1600-1400,1527$, 1350, 1273, 740; HRMS (ESI) $m / z$, calcd. for $\mathrm{C}_{14} \mathrm{H}_{8} \mathrm{ClN}_{3} \mathrm{O}_{3}$ $[\mathrm{M}+\mathrm{H}]^{+}:$302.0327, found: 302.0324 .

3-(4-Chlorophenyl)-5-(4-nitrophenyl)-1,2,4-oxadiazole (28)

Yield: 45\%; mp 154-156 ${ }^{\circ} \mathrm{C}$; ${ }^{1} \mathrm{H}$ NMR $(400.00 \mathrm{MHz}$, $\left.\mathrm{CDCl}_{3}\right) \delta 8.41(\mathrm{~m}, 4 \mathrm{H}), 8.12(\mathrm{~d}, 2 \mathrm{H}, J 8.4 \mathrm{~Hz}), 7.51(\mathrm{~d}, 2 \mathrm{H}$, $J 8.8 \mathrm{~Hz}) ;{ }^{13} \mathrm{C} \mathrm{NMR}\left(100.0 \mathrm{MHz}, \mathrm{CDCl}_{3}\right) \delta 173.8,168.6$, $150.3,137.8,129.3,129.2,129.2,128.9,124.8,124.4$; IR $(\mathrm{KBr}) \vee / \mathrm{cm}^{-1} 1580,1559,1519,1407,1347,1091$, 840, 742, 715; HRMS (ESI) $\mathrm{m} / z$, calcd. for $\mathrm{C}_{14} \mathrm{H}_{8} \mathrm{ClN}_{3} \mathrm{O}_{3}$ $[\mathrm{M}+\mathrm{H}]^{+}:$302.0327, found: 302.0328 .

3-(4-Chlorophenyl)-5-(3,5-dinitrophenyl)-1,2,4-oxadiazole (29)

Yield: 47\%; mp decomp.; ${ }^{1} \mathrm{H}$ NMR (400.00 MHz, $\left.\mathrm{CDCl}_{3}\right) \delta 9.17$ (sd, 2H, J 2.4 Hz), 9.10 (st, 1H, J 2.0 Hz), $8.20(\mathrm{~d}, 2 \mathrm{H}, J 8.8 \mathrm{~Hz}), 7.73(\mathrm{~d}, 2 \mathrm{H}, J 8.8 \mathrm{~Hz}) ;{ }^{13} \mathrm{C} \mathrm{NMR}$ $\left(100.0 \mathrm{MHz}, \mathrm{CDCl}_{3}\right) \delta 173.1,168.3,149.1,137.3,130.0$, 129.5, 128.7, 128.2, 126.3, 124.8; IR (KBr) v / cm $\mathrm{cm}^{-1} 1598$, 1537, 1469, 1405, 1338, 1095, 853, 763, 720; HRMS (ESI) $m / z$, calcd. for $\mathrm{C}_{14} \mathrm{H}_{7} \mathrm{ClN}_{4} \mathrm{O}_{5}[\mathrm{M}+\mathrm{H}]^{+}:$347.0105, found: 347.0110 .

3-(4-Chlorophenyl)-5-(2-chloro-5-nitrophenyl)-1,2,4-oxadiazole (30)

Yield: 48\%; mp 212-214 ${ }^{\circ} \mathrm{C} ;{ }^{1} \mathrm{H}$ NMR (400.00 MHz, $\left.\mathrm{CDCl}_{3}\right) \delta 9.06(\mathrm{sd}, 1 \mathrm{H}, J 2.4 \mathrm{~Hz}), 8.39$ (dd, 1H, J 8.8, $2.4 \mathrm{~Hz}), 8.15$ (d, 2H, J 8.4 Hz), 7.82 (d, 1H, J 8.8 Hz), 7.53 $(\mathrm{d}, 2 \mathrm{H}, J 8.4 \mathrm{~Hz}) ;{ }^{13} \mathrm{C} \mathrm{NMR}\left(100.0 \mathrm{MHz}, \mathrm{CDCl}_{3}\right) \delta 172.6$, $168.2,146.5,140.5,137.9,132.8,129.4,129.0,127.3$, 127.1, 124.7, 124.7; IR (KBr) v / cm ${ }^{-1} 1527,1411,1350$, $1095,833,732$; HRMS (ESI) $m / z$, calcd. for $\mathrm{C}_{14} \mathrm{H}_{7} \mathrm{Cl}_{2} \mathrm{~N}_{3} \mathrm{O}_{3}$ $[\mathrm{M}+\mathrm{H}]^{+}:$335.9864, found: 335.9868 .

\section{3-Phenyl-5-(2-nitrophenyl)-1,2,4-oxadiazole (31)}

Yield: 47\%; mp 87-89 ${ }^{\circ} \mathrm{C}$; ${ }^{1} \mathrm{H}$ NMR $(600.00 \mathrm{MHz}$, $\left.\mathrm{CDCl}_{3}\right) \delta 8.15(\mathrm{~d}, 2 \mathrm{H}, J 6.6 \mathrm{~Hz}), 8.04(\mathrm{~m}, 2 \mathrm{H}), 7.80(\mathrm{~m}$, $2 \mathrm{H}), 7.53(\mathrm{~m}, 3 \mathrm{H}) ;{ }^{13} \mathrm{C} \mathrm{NMR}\left(150.0 \mathrm{MHz}, \mathrm{CDCl}_{3}\right) \delta 172.6$, 169.2, 149.0, 133.2, 133.1, 131.7, 131.5, 129.1, 127.8, 126.5, 124.8, 119.3; IR (KBr) v / cm $\mathrm{cm}^{-1} 1527,1441,1355$, 1300, 910, 851, 791, 723, 687, 579; HRMS (ESI) $\mathrm{m} / \mathrm{z}$, calcd. for $\mathrm{C}_{14} \mathrm{H}_{9} \mathrm{~N}_{3} \mathrm{O}_{3}[\mathrm{M}+\mathrm{H}]^{+}:$268.0644, found: 268.0651 .

3-(3-Chlorophenyl)-5-(2-nitrophenyl)-1,2,4-oxadiazole (32)

Yield: 50\%; mp 95-97 ${ }^{\circ} \mathrm{C}$; ${ }^{1} \mathrm{H}$ NMR $(400.00 \mathrm{MHz}$, $\left.\mathrm{CDCl}_{3}\right) \delta 8.13(\mathrm{t}, 1 \mathrm{H}, J 1.6 \mathrm{~Hz}), 8.04(\mathrm{~m}, 3 \mathrm{H}), 7.81(\mathrm{~m}$, 2H), 7.52 (dt, 1H, J 8.0, $1.2 \mathrm{~Hz}), 7.45(\mathrm{t}, 1 \mathrm{H}, J 7.6 \mathrm{~Hz}$ ); ${ }^{13} \mathrm{C} \mathrm{NMR}\left(100.0 \mathrm{MHz}, \mathrm{CDCl}_{3}\right) \delta 172.8,168.0,148.7,135.0$, 133.2, 133.0, 131.6, 131.4, 130.3, 128.0, 127.7, 125.7, 124.7, 118.9; IR (KBr) v / cm ${ }^{-1} 1529,1434,1355,1340$, 768, 744, 683; HRMS (ESI) $m / z$, calcd. for $\mathrm{C}_{14} \mathrm{H}_{8} \mathrm{ClN}_{3} \mathrm{O}_{3}$ $[\mathrm{M}+\mathrm{H}]^{+}:$302.0327, found: 302.0260 .

\section{3-(3-Pyridyl)-5-phenyl-1,2,4-oxadiazole (33)}

Yield: 64\%; mp 194-196 ${ }^{\circ} \mathrm{C} ;{ }^{1} \mathrm{H}$ NMR $(400.00 \mathrm{MHz}$, $\left.\mathrm{CDCl}_{3}\right) \delta 8.99(\mathrm{~d}, 1 \mathrm{H}, J 2.0 \mathrm{~Hz}), 8.75(\mathrm{dd}, 1 \mathrm{H}, J 4.8,1.6 \mathrm{~Hz})$, $8.15(\mathrm{dt}, 1 \mathrm{H}, J 8.0,2.0 \mathrm{~Hz}), 8.10(\mathrm{~d}, 2 \mathrm{H}, J 7.2 \mathrm{~Hz}), 7.62(\mathrm{t}$, $1 \mathrm{H}, J 7.6 \mathrm{~Hz}), 7.50(\mathrm{t}, 2 \mathrm{H}, J 8.0 \mathrm{~Hz}), 7.40(\mathrm{~m}, 1 \mathrm{H}) ;{ }^{13} \mathrm{C} \mathrm{NMR}$ $\left(100.0 \mathrm{MHz}, \mathrm{CDCl}_{3}\right) \delta 163.8,154.9,152.2,147.7,134.8$, 133.2, 129.5, 129.3, 128.6, 127.4, 123.6; IR (KBr) v / cm ${ }^{-1}$ 3421, 3327, 3064, 1724, 1632, 1604, 1561, 1448, 1396, 1263, 1090, 1067, 1023, 930, 814, 698; HRMS (ESI) $\mathrm{m} / \mathrm{z}$, calcd. for $\mathrm{C}_{13} \mathrm{H}_{9} \mathrm{~N}_{3} \mathrm{O}[\mathrm{M}+\mathrm{H}]^{+}:$224.0746, found: 224.0751 .

3-(3-Pyridyl)-5-(2-chlorophenyl)-1,2,4-oxadiazole (34)

Yield: 52\%; mp 83-85 ${ }^{\circ} \mathrm{C} ;{ }^{1} \mathrm{H}$ NMR $(600.00 \mathrm{MHz}$, $\left.\mathrm{CDCl}_{3}\right) \delta 9.42(\mathrm{~s}, 1 \mathrm{H}), 8.78(\mathrm{dd}, 1 \mathrm{H}, J 4.8,1.2 \mathrm{~Hz}), 8.48$ (dt, 1H, J 8.4, 1.2 Hz), 8.18 (dd, 1H, J 7.8, 1.2 Hz), 7.62 (dd, 1H, J 8.4, 0.6 Hz), 7.55 (td, 1H, J 7.8, 1.2 Hz), 7.47 $(\mathrm{m}, 2 \mathrm{H}) ;{ }^{13} \mathrm{C} \mathrm{NMR}\left(150.0 \mathrm{MHz}, \mathrm{CDCl}_{3}\right) \delta 174.8,166.7$, 152.0, 148.6, 134.9, 134.0, 133.3, 131.9, 131.5, 127.1, 
123.7, 123.3, 123.1; IR (KBr) v / cm $\mathrm{cm}^{-1} 1595,1583,1407$, 1364, 739, 700; HRMS (ESI) $\mathrm{m} / 2$, calcd. for $\mathrm{C}_{13} \mathrm{H}_{8} \mathrm{ClN}_{3} \mathrm{O}$ $[\mathrm{M}+\mathrm{H}]^{+}:$258.0429, found: 258.0433 .

3-(3-Pyridyl)-5-(2-bromophenyl)-1,2,4-oxadiazole (35) Yield: 45\%; mp 90-92 ${ }^{\circ} \mathrm{C}$; ${ }^{1} \mathrm{H}$ NMR $(600.00 \mathrm{MHz}$, $\left.\mathrm{CDCl}_{3}\right) \delta 9.43(\mathrm{~s}, 1 \mathrm{H}), 8.80(\mathrm{~d}, 1 \mathrm{H}, J 4.2 \mathrm{~Hz}), 8.48(\mathrm{dt}, 1 \mathrm{H}$, $J$ 7.8, $1.8 \mathrm{~Hz}), 8.12(\mathrm{dd}, 1 \mathrm{H}, J$ 7.8, $1.2 \mathrm{~Hz}), 7.83(\mathrm{~d}, 1 \mathrm{H}$, $J 7.8 \mathrm{~Hz}), 7.50$ (m, 3H); ${ }^{13} \mathrm{C}$ NMR $\left(150.0 \mathrm{MHz}, \mathrm{CDCl}_{3}\right)$ $\delta 175.3,166.7,151.9,148.6,135.0,134.9,133.4,132.2$, $127.7,125.3,123.7,123.2,122.2$; IR (KBr) v / cm ${ }^{-1} 1599$, 1407, 1366, 1024, 741, 702, 645; HRMS (ESI) $\mathrm{m} / z$, calcd. for $\mathrm{C}_{13} \mathrm{H}_{8} \mathrm{BrN}_{3} \mathrm{O}[\mathrm{M}+\mathrm{H}]^{+}$: 301.9923, found: 301.9924 .

\section{3-(3-Pyridyl)-5-(2-iodophenyl)-1,2,4-oxadiazole (36)}

Yield: 46\%; mp 84-86 ${ }^{\circ} \mathrm{C}$; ${ }^{1} \mathrm{H}$ NMR $(400.00 \mathrm{MHz}$, $\left.\mathrm{CDCl}_{3}\right) \delta 9.44(\mathrm{~d}, 1 \mathrm{H}, J 2.0 \mathrm{~Hz}), 8.82(\mathrm{dd}, 1 \mathrm{H}, J 4.8,1.6 \mathrm{~Hz})$, $8.49(\mathrm{dt}, 1 \mathrm{H}, J 8.0,1.6 \mathrm{~Hz}), 8.14(\mathrm{~d}, 1 \mathrm{H}, J 8.0 \mathrm{~Hz}), 8.03$ (dd, 1H, $J$ 8.0, $1.6 \mathrm{~Hz}), 7.55$ (t, 1H, $J 7.6 \mathrm{~Hz}), 7.50$ (m, 1H), 7.27 (td, 1H, J 7.6, $1.6 \mathrm{~Hz}) ;{ }^{13} \mathrm{C}$ NMR (100.0 MHz, $\left.\mathrm{CDCl}_{3}\right) \delta 176.0,166.6,151.8,148.5,141.8,135.1,133.2$, 131.8, 129.0, 128.5, 123.9, 123.3, 94.5; IR (KBr) v / $\mathrm{cm}^{-1}$ 1705, 1581, 1405, 1366, 1017, 736, 697; HRMS (ESI) $\mathrm{m} / \mathrm{z}$, calcd. for $\mathrm{C}_{13} \mathrm{H}_{8} \mathrm{IN}{ }_{3} \mathrm{O}[\mathrm{M}+\mathrm{H}]^{+}: 349.9785$, found: 349.9786 .

3-(3-Pyridyl)-5-(3,5-dinitrophenyl)-1,2,4-oxadiazole (37)

Yield: $45 \%$; mp 137-139 ${ }^{\circ} \mathrm{C}$; ${ }^{1} \mathrm{H}$ NMR $(400.00 \mathrm{MHz}$, DMSO- $\left.d_{6}\right) \delta 9.32(\mathrm{sd}, 1 \mathrm{H}, J 1.6 \mathrm{~Hz}), 9.18(\mathrm{sd}, 2 \mathrm{H}$, $J 2.0 \mathrm{~Hz}$ ), 9.10 (st, $1 \mathrm{H}, J 2.0 \mathrm{~Hz}), 8.85$ (dd, $1 \mathrm{H}, J 4.8$, $1.6 \mathrm{~Hz}), 8.53(\mathrm{dt}, 1 \mathrm{H}, J 8.0,2.0 \mathrm{~Hz}), 7.68(\mathrm{t}, 1 \mathrm{H}, J 4.8 \mathrm{~Hz})$; ${ }^{13} \mathrm{C}$ NMR $\left(100.0 \mathrm{MHz}\right.$, DMSO- $\left.d_{6}\right) \delta 173.2,167.4,153.3$, 149.2, 148.4, 135.4, 128.4, 126.3, 124.9, 122.9, 122.4; IR $(\mathrm{KBr}) \vee / \mathrm{cm}^{-1} 1679,1636,1602,1533,1344,918,726$, 704, 654; HRMS (ESI) $m / z$, calcd. for $\mathrm{C}_{13} \mathrm{H}_{7} \mathrm{~N}_{5} \mathrm{O}_{5}[\mathrm{M}+\mathrm{H}]^{+}$: 314.0447, found: 314.0440 .

3-(3-Pyridyl)-5-(3-nitrophenyl)-1,2,4-oxadiazole (38)

Yield: 46\%; mp 142-144 ${ }^{\circ} \mathrm{C}$; ${ }^{1} \mathrm{H}$ NMR $(400.00 \mathrm{MHz}$, $\left.\mathrm{CDCl}_{3}\right) \delta 9.06(\mathrm{~s}, 1 \mathrm{H}), 8.54(\mathrm{~d}, 1 \mathrm{H}, J 7.6 \mathrm{~Hz}), 8.49(\mathrm{~d}, 1 \mathrm{H}$, $J 8.0 \mathrm{~Hz}), 8.17(\mathrm{~s}, 1 \mathrm{H}), 8.07(\mathrm{~d}, 1 \mathrm{H}, J 7.2 \mathrm{~Hz}), 7.80(\mathrm{t}, 1 \mathrm{H}$, $J 8.0 \mathrm{~Hz}), 7.53$ (d, 1H, J 7.6 Hz), $7.46(\mathrm{t}, 1 \mathrm{H}, J 7.6 \mathrm{~Hz}$ ); ${ }^{13} \mathrm{C}$ NMR $\left(100.0 \mathrm{MHz}, \mathrm{CDCl}_{3}\right) \delta 173.8,168.3,148.7$, 135.1, 133.5, 131.6, 130.5, 130.3, 128.0, 127.7, 127.2, 126.7, 125.6, 123.2; IR (KBr) v / $\mathrm{cm}^{-1} 1623,1525,1409$, $1345,731,678$; HRMS (ESI) $m / z$, calcd. for $\mathrm{C}_{13} \mathrm{H}_{8} \mathrm{~N}_{4} \mathrm{O}_{3}$ $[\mathrm{M}+\mathrm{H}]^{+}: 269.0596$, found: 269.0670 .

3-(4-Chlorophenyl)-5-(2-hydroxyphenyl)-1,2,4-oxadiazole (39)

Yield: $45 \%$; mp $156-158{ }^{\circ} \mathrm{C}$; ${ }^{1} \mathrm{H}$ NMR $(400.00 \mathrm{MHz}$, $\left.\mathrm{CDCl}_{3}\right) \delta 10.40(\mathrm{~s}, 1 \mathrm{H}), 8.07$ (d, 2H, J $\left.6.8 \mathrm{~Hz}\right), 8.01(\mathrm{~d}$,
2H, J 7.2 Hz), 7.53 (m, 3H), 7.16 (d, 1H, J $6.4 \mathrm{~Hz}), 7.06$ (t, $1 \mathrm{H}, J 6.0 \mathrm{~Hz}) ;{ }^{13} \mathrm{C} \mathrm{NMR}\left(100.0 \mathrm{MHz}, \mathrm{CDCl}_{3}\right) \delta 174.7$, 166.5, 158.3, 138.1, 135.6, 129.6, 129.0, 128.1, 124.5, 120.4, 118.1, 108.2; IR (KBr) v / cm c $^{-1} 3166,3133,1625$, 1593, 1551, 1482, 1406, 1362, 1231, 1088, 830, 751, 658; HRMS (ESI) $\mathrm{m} / z$, calcd. for $\mathrm{C}_{14} \mathrm{H}_{9} \mathrm{ClN}_{2} \mathrm{O}_{2}[\mathrm{M}+\mathrm{H}]^{+}$: 273.0353, found: 273.0358 .

\section{Evaluation of biological activity}

The antibacterial assay evaluated Gram-negative (Escherichia coli American Type Culture Collection (ATCC) 25922, Pseudomonas aeruginosa ATCC 27853 and Proteus mirabilis ATCC 25933) and Gram-positive bacteria (Staphylococcus aureus ATCC 25923 and Enterococcus faecalis ATCC 29212). These microorganisms were first placed in Mueller-Hinton broth and maintained for $24 \mathrm{~h}$ at $37^{\circ} \mathrm{C}$.

The microbial suspensions were prepared by comparing turbidity with the MacFarland scale standard No. 0.5 for the preliminary determination of activity. ${ }^{21}$ The suspensions in question were seeded by continuous induction in Petri dishes containing Mueller-Hinton agar medium with the aid of a swab. Then, $100 \mu \mathrm{M}$ solution of each test compound, in $20 \%$ DMSO, were added to the plate. There was one plate for each bacterium being tested. The assays were performed in duplicate.

The blank (negative) assay with 20\% DMSO and the positive control for antibacterial activity used the antibiotic amoxicillin $(100 \mu \mathrm{M})$. Plates were incubated at $37{ }^{\circ} \mathrm{C}$ for $24 \mathrm{~h}$. After this period, the results were obtained by observing the formation of the inhibition halos. ${ }^{21}$

\section{MIC determination assays}

In the assays to determine MIC, the compounds under evaluation were used in different concentrations, obtained by successive dilution of a stock solution. ${ }^{22}$ Concentrations of $100,75,50$ and $25 \mu \mathrm{M}$ were initially used to define the range at which the minimum inhibitory concentration was localized. Subsequently, serial dilutions were made using narrower concentration ranges.

Control assays were: (i) with Mueller-Hinton broth, 20\% DMSO solution and bacterial suspension; (ii) only broth and 20\% DMSO solution; (iii) with 20\% DMSO solution, broth and the test substance; and (iv) with a commercial antibiotic solution of amoxicillin and broth with bacteria. All assays were performed at the same concentrations described above for the synthesized products. Observation of turbidity in the wells of the plate was done with the naked eye. All assays were performed in triplicate. 


\section{Results and Discussion}

\section{Synthesis of the 1,2,4-oxadiazol derivatives (20-39)}

Initially, the treatment of the nitrile derivatives with hydroxylamine hydrochloride produced the respective amidoximes in yields of about $98 \%$, which reacted with the carboxylic acid chlorides yielding the 1,2,4-oxadiazole nuclei (Scheme 1).

According to the literature, derivatives containing homoaromatic rings ${ }^{23-26}$ and heteroaromatic ${ }^{13}$ compounds, such as benzene and pyridine, exhibit antimicrobial properties. Thus, new compounds have been synthesized using the concept of molecular hybridization ${ }^{27}$ by combining pharmacophore groups of different structures. Some substitution patterns were adopted for both aromatic rings based on structures reported in the literature (Figure 3).

Based on this information, twenty oxadiazole derivatives were synthesized using benzonitrile (1), 4-chlorobenzonitrile (2), 3-chlorobenzonitrile (3), and 3-cyanopyridine (4). This strategy aimed to investigate the influence of the different substituents and their positions on the bioactivity of the synthesized products. The synthesis strategy employed carboxylic acids containing halogens and nitro groups as substituents at different positions (Table 1).

The compounds were synthesized based on the structural skeleton reported in Table $1,{ }^{25,26,39}$ which has the central 1,2,4-oxadiazole nucleus and phenyl radicals linked at the C-3 and C-5 positions of the heterocycle. Thus, two sets of compounds involving chlorinated and pyridine derivatives were synthesized.

Initially, for the comparative effect of the two sets of molecules, a basic compound without any type of substitution was synthesized (20). Two compounds (21 and 33) derived from $p$-chlorobenzonitrile and 3-cyanopyridine, respectively, were synthesized as template molecules of each set, as shown in Scheme 2.

From compound 21, a series with different halogen atoms at the ortho position of the aromatic ring attached to the C-5 heterocycle was synthesized (Figure 4). This selection is associated with the importance of halogens as pharmacophoric groups present in the structure of antimicrobial compounds. ${ }^{40}$ The purpose of this series was to evaluate the influence of halogen atoms on the C-ring. Compounds 22, 23, 24 substituted with $-\mathrm{Cl},-\mathrm{Br}$ and $-\mathrm{I}$ in the ortho position of the C-ring were synthesized. In order to investigate the influence of the substituent position on the bioactivity, the meta-brominated (25) isomer was synthesized.

The literature classifies the nitro $\left(-\mathrm{NO}_{2}\right)$ substituent as a pharmacophore of great importance in the chemistry of antibiotics, which is also present in the structure of known antibacterials, such as chloramphenicol. ${ }^{41,42}$ Thus, the three nitrated isomers $(\mathbf{2 6}, \mathbf{2 7}, \mathbf{2 8})$ were synthesized (Figure 5) in order to investigate the influence of this substituent.

In addition, two new derivatives containing two nitro groups (29) and one chlorinated-nitrated compound (30) were synthesized (Figure 5). The insertion of the second nitro group in $\mathbf{1 0}$ had as main goal to increase the inhibition efficiency, while that of the chlorine atom aimed to favor a higher lipophilicity, considering that this parameter influences the antibacterial activity. ${ }^{40}$ Following the same strategy, a compound containing the C-ring mononitrated and no substituents on A-ring (31) was synthesized in order to check whether the absence of the chlorine atom would influence the potential bioactivity. Finally, a compound with a meta-chlorinated substitution pattern on the ring A (32) was synthesized to evaluate the effect of the change of position of the chlorine.<smiles>N#CSCc1nc(-c2ccc(Cl)cc2)no1</smiles>

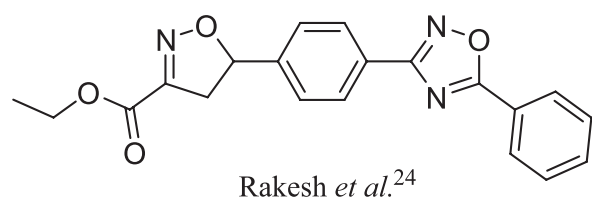

Mycobacterium tuberculosis $\mathrm{MIC}=3.125 \mu \mathrm{g} \mathrm{mL}^{-1}$
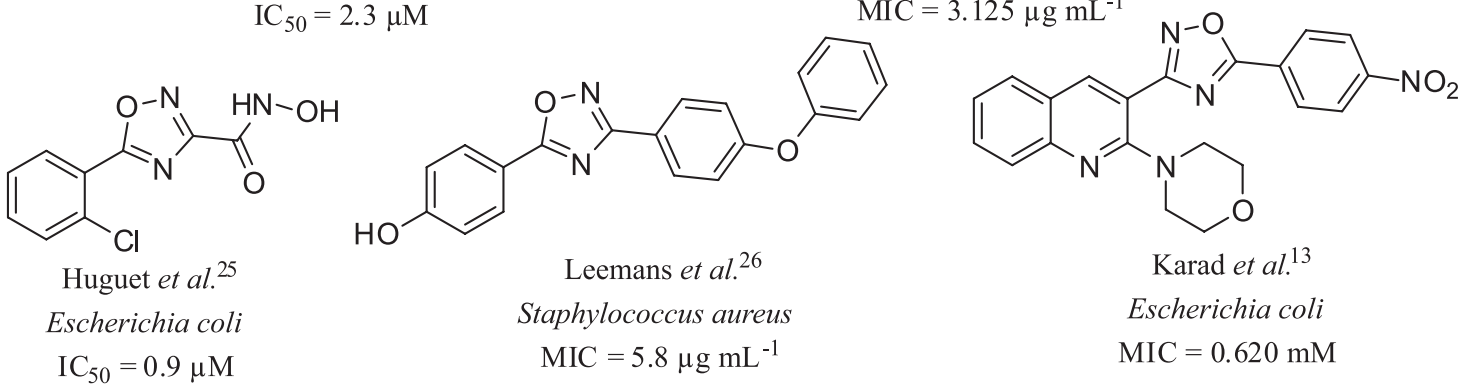

Figure 3. Examples of antimicrobial oxadiazole derivatives. 
Table 1. Structure, yield and melting points of synthesized heterocycles

\begin{tabular}{|c|c|c|c|c|c|c|}
\hline \multirow{2}{*}{ Compound } & \multicolumn{4}{|c|}{ Substituent } & \multirow{2}{*}{ Yield / \% } & \multirow{2}{*}{ Melting point $\mathrm{t}^{\mathrm{a}} /{ }^{\circ} \mathrm{C}$} \\
\hline & $\mathrm{R}^{1}$ & $\mathrm{R}^{2}$ & $\mathrm{R}^{3}$ & $\mathrm{X}$ & & \\
\hline 20 & - & $\mathrm{H}$ & - & $\mathrm{C}$ & 76 & $108-110(110)^{28}$ \\
\hline 21 & $4-\mathrm{Cl}$ & $\mathrm{H}$ & - & $\mathrm{C}$ & 68 & $111-113(112)^{29}$ \\
\hline 22 & $4-\mathrm{Cl}$ & $2-\mathrm{Cl}$ & - & $\mathrm{C}$ & 49 & $128-130(128)^{30}$ \\
\hline 23 & $4-\mathrm{Cl}$ & $2-\mathrm{Br}$ & - & $\mathrm{C}$ & 42 & $130-134$ \\
\hline 24 & $4-\mathrm{Cl}$ & $2-\mathrm{I}$ & - & $\mathrm{C}$ & 40 & $91-93$ \\
\hline 25 & $4-\mathrm{Cl}$ & $3-\mathrm{Br}$ & - & $\mathrm{C}$ & 45 & $159-161$ \\
\hline 26 & $4-\mathrm{Cl}$ & $2-\mathrm{NO}_{2}$ & - & $\mathrm{C}$ & 51 & $137-139$ \\
\hline 27 & $4-\mathrm{Cl}$ & $3-\mathrm{NO}_{2}$ & - & $\mathrm{C}$ & 44 & $168-170(168)^{31}$ \\
\hline 28 & $4-\mathrm{Cl}$ & $4-\mathrm{NO}_{2}$ & - & $\mathrm{C}$ & 38 & $154-156(154-156)^{32}$ \\
\hline 29 & $4-\mathrm{Cl}$ & $3-\mathrm{NO}_{2}$ & $5-\mathrm{NO}_{2}$ & $\mathrm{C}$ & 47 & decomposed \\
\hline 30 & $4-\mathrm{Cl}$ & $2-\mathrm{Cl}$ & $5-\mathrm{NO}_{2}$ & $\mathrm{C}$ & 44 & $212-214(213)^{33}$ \\
\hline 31 & - & $2-\mathrm{NO}_{2}$ & - & $\mathrm{C}$ & 43 & $87-89(88-90)^{34}$ \\
\hline 32 & $3-\mathrm{Cl}$ & $2-\mathrm{NO}_{2}$ & - & $\mathrm{C}$ & 40 & 95-97 \\
\hline 33 & - & $\mathrm{H}$ & - & $\mathrm{N}$ & 64 & $194-196(196)^{35}$ \\
\hline 34 & - & $2-\mathrm{Cl}$ & - & $\mathrm{N}$ & 52 & $83-85(86)^{36}$ \\
\hline 35 & - & $2-\mathrm{Br}$ & - & $\mathrm{N}$ & 38 & $90-92$ \\
\hline 36 & - & $2-\mathrm{I}$ & - & $\mathrm{N}$ & 41 & $84-86$ \\
\hline 37 & - & $3-\mathrm{NO}_{2}$ & $5-\mathrm{NO}_{2}$ & $\mathrm{~N}$ & 43 & $137-139$ \\
\hline 38 & - & $3-\mathrm{NO}_{2}$ & - & $\mathrm{N}$ & 46 & $142-144(142-144)^{37}$ \\
\hline 39 & $4-\mathrm{Cl}$ & $2-\mathrm{OH}$ & - & $\mathrm{C}$ & 45 & $156-158(156-157)^{38}$ \\
\hline
\end{tabular}

${ }^{\mathrm{a}}$ Compounds without the reference value in parentheses are unpublished.<smiles>CC=CC</smiles>

Substituted chlorinated series (halogens, nitro)<smiles>c1ccc(-c2noc(-c3ccccc3)n2)cc1</smiles>

20
33

Substituted pyridinic series (halogens, nitro)

Scheme 2. General design strategy for the compound sets and series.<smiles></smiles><smiles>Clc1ccc(-c2noc(-c3cccc(Br)c3)n2)cc1</smiles>

$23-\mathrm{X}=\mathrm{Br}$

$24-X=I$

Figure 4. Oxadiazole derivatives containing aryl halides bound to the C-5 of the heterocycle ring. 
<smiles>O=[N+]([O-])c1cccc(-c2nc(-c3ccc(Cl)cc3)no2)c1</smiles>

$26-2-\mathrm{NO}_{2}$

$27-3-\mathrm{NO}_{2}$

28 - 4- $\mathrm{NO}_{2}$<smiles>O=[N+]([O-])c1ccccc1-c1nc(-c2ccccc2)no1</smiles>

31<smiles>O=[N+]([O-])c1cc(-c2nc(-c3ccc(Cl)cc3)no2)cc([N+](=O)[O-])c1</smiles>

29<smiles>O=[N+]([O-])c1ccccc1-c1nc(-c2cccc(Cl)c2)no1</smiles><smiles>O=[N+]([O-])c1ccc(Cl)c(-c2nc(-c3ccc(Cl)cc3)no2)c1</smiles>

30<smiles>O=C(N[C@H](CO)[C@H](O)c1ccc([N+](=O)[O-])cc1)C(Cl)Cl</smiles>

Figure 5. Oxadiazole derivatives containing phenyl nitro radical bonded to the C-5 of the heterocycle.

In continuity, six compounds containing a heteroaromatic substituent were synthesized using the strategy adopted for the first set of compounds. The synthesis strategy employed cyano-pyridine, since the literature reports that $1,2,4$-oxadiazole rings containing the pyridyl radical as substituent have antibacterial activity (Figure 6). ${ }^{13}$ The substitution of the phenyl by a pyridyl radical, bound to the $\mathrm{C}-3$ of the heterocycle, has focused on increasing the polarization of the compound, as well as enabling hydrogen bonding interactions, ${ }^{40}$ which are relevant within the biological context. In this manner, a standard compound (33), which did not have substituents on the aromatic rings, was synthesized. In the following, different halogens $(-\mathrm{Cl},-\mathrm{Br}$ and $-\mathrm{I})$ were inserted onto the homoaromatic ring. The products $\mathbf{3 4 - 3 6}$ were synthesized in order to compare these compounds with their analogs synthesized in the first group (Figure 6).<smiles>[X]c1ccccc1-c1nc(-c2cccnc2)no1</smiles>

$33-\mathrm{X}=\mathrm{H}$
$34-\mathrm{X}=\mathrm{Cl}$
$35-\mathrm{X}=\mathrm{Br}$
$36-\mathrm{X}=\mathrm{I}$

Figure 6. Oxadiazole derivatives containing pyridyl radical bound to the $\mathrm{C}-3$ of the heterocycle.

In a similar way to the set of chlorinated compounds, two nitrated (37 and $\mathbf{3 8}$ ) compounds and one containing a hydroxyl (activator) group (39) were synthesized to verify the influence of these groups on the bioactivity (Figure 7).

\section{Assays for antibacterial activity}

Table 2 presents the preliminary results of the antibacterial properties of the synthesized compounds using the agar dilution technique. These assays were conducted using a concentration of $100 \mu \mathrm{M}$. This value was established as the desired activity parameter as other studies using concentrations close to this value were found in the literature..$^{43}$

The results in Table 2 indicate that some of the compounds synthesized were able to inhibit the bacteria P. mirabilis, E. faecalis and E. coli. However, none of the compounds showed activity against $S$. aureus and P. aeruginosa.

Compounds 23, 26, 27, 28, 30, 32 and 38, which showed inhibition of the three bacteria mentioned above, were selected for determination of the MIC values. Serial dilutions of the solutions of the compounds together with the broth containing the bacteria analyzed in this step were conducted for these assays. First, a wide concentration range was used $(100,75,50$ and $25 \mu \mathrm{M})$, and then gradually narrowed. Table 3 shows the results of the MIC values found for the assays with the bacteria P. mirabilis, E. coli and E. faecalis.

The results of the MIC assays (Table 3) show that compounds $\mathbf{2 6}$ and $\mathbf{3 0}$ provided the best results, followed by compound 27 . These compounds showed MIC values around 60, 62 and $68 \mu \mathrm{M}$ for E. coli, respectively, and they presented values of 72,72 , and $76 \mu \mathrm{M}$ for P. mirabilis,<smiles>O=[N+]([O-])c1cc(-c2nc(-c3cccnc3)no2)cc([N+](=O)[O-])c1</smiles><smiles>O=[N+]([O-])c1cccc(-c2nc(-c3cccnc3)no2)c1</smiles>

38<smiles>Oc1ccccc1-c1nc(-c2ccc(Cl)cc2)no1</smiles>

39

Figure 7. Oxadiazole derivatives containing nitro and hydroxyl groups as substituent. 
Table 2. Results of preliminary activity assays

\begin{tabular}{|c|c|c|c|}
\hline \multirow{2}{*}{ Compound } & \multicolumn{3}{|c|}{ Bacterium $^{a}$} \\
\hline & P. mirabilis & E. faecalis & E. coli \\
\hline 20 & - & - & - \\
\hline 21 & - & - & - \\
\hline 22 & - & - & - \\
\hline 23 & + & + & + \\
\hline 24 & - & - & - \\
\hline 25 & - & - & - \\
\hline 26 & + & + & + \\
\hline 27 & + & + & + \\
\hline 28 & + & + & + \\
\hline 29 & - & - & - \\
\hline 30 & + & + & + \\
\hline 31 & + & - & + \\
\hline 32 & + & - & + \\
\hline 33 & - & - & - \\
\hline 34 & - & - & - \\
\hline 35 & - & - & - \\
\hline 36 & - & - & - \\
\hline 37 & - & - & - \\
\hline 38 & + & - & + \\
\hline 39 & - & - & - \\
\hline Amoxicillin & + & + & + \\
\hline
\end{tabular}

${ }^{a} P$. aeruginosa and $S$. aureus were resistant to the synthesized compounds. The signals indicate that the bacteria were sensitive (+) or resistant (-).

respectively. All three compounds had lower inhibition efficiency (ca. $100 \mu \mathrm{M}$ ) against E. faecalis.

Comparing the structures of the eight heterocycles that showed activity against the evaluated microorganisms, seven of them contained the nitro group, only compound $\mathbf{2 3}$ did not. The results in Table 3 indicate that the nitro group provided an improved inhibition efficiency compared to the compound (23) independently of its position on the ring.

The analysis of the results for compounds $\mathbf{2 6 , 2 7}$ and $\mathbf{2 8}$, where the nitro substituents are in different positions $(o, m$, $p$ ) suggests that the nitro group favors inhibition of bacterial growth. Also, the position of this substituent results in a small influence on the final activity of the compound.

The results obtained for compounds $\mathbf{2 7}$ and $\mathbf{3 8}$ with $p$-chlorophenyl and pyridyl radicals, respectively, attached to the C-3 of the heterocycle showed that compound $\mathbf{2 7}$ had better inhibition efficiency.

Inhibition capacity of compound $\mathbf{2 6}$, which contains a chlorine atom at the para position, provided the best result compared to $\mathbf{3 2}$, containing the same halogen atom at the meta position. A similar result was observed for compounds $\mathbf{2 3}$ and $\mathbf{2 5}$, where the latter was inactive, confirming that the change in position of the substituent decisively affected the activity.

The biological results of the heterocycles were correlated with the physicochemical data (solubility parameter $(\log \mathrm{P})$ and the polar surface area (PSA)), which were obtained using the online software Molinspiration. ${ }^{45}$ The results for all compounds are shown in Table 4.

Correlating the MIC values and physicochemical data for compounds $\mathbf{2 6}, \mathbf{2 7}$ and $\mathbf{2 8}$, where the nitro groups are in different positions, inhibition efficiencies in the order ortho $(\mathbf{2 6})>$ meta $(\mathbf{2 7})>$ para $(\mathbf{2 8})$ were observed. The physicochemical parameters for these three compounds showed very close values for $\log$ P and PSA. Therefore, it is assumed that these factors should not be considered responsible for the different bioactivities found, and the ratio of observed differences is probably a spatial question.

Compounds $\mathbf{2 7}$ and $\mathbf{3 0}$ have the same structure, except for the insertion of the chlorine atom at the C-2-position of the C-ring in compound 30, which showed slightly better bacterial inhibition efficiency. This may have been influenced by the higher lipophilicity of this compound, as observed by the $\log \mathrm{P}$ values in Table 4 . The results of Table 3 indicate that compound $\mathbf{3 1}$ showed low antibacterial activity against all bacteria. This factor suggests that the presence of the chlorine atom in the A ring influences the activity.

The only active compound (38), in the pyridine set, showed low antibacterial activity. It is a mononitrated compound, which, according to Table 4 , has a $\log \mathrm{P}=2.59$, considerably lower than the compounds with the higher

Table 3. Minimum inhibitory concentration (MIC) values for the bioactive synthesized heterocycles

\begin{tabular}{|c|c|c|c|c|c|c|c|c|c|}
\hline \multirow{3}{*}{ Bacterium } & \multicolumn{9}{|c|}{$\mathrm{MIC}^{\mathrm{a}} / \mu \mathrm{M}$} \\
\hline & \multicolumn{9}{|c|}{ Compound } \\
\hline & 23 & 26 & 27 & 28 & 30 & 31 & 32 & 38 & Amoxicillin \\
\hline P. mirabilis & 86 & 72 & 76 & 86 & 72 & 100 & 98 & 95 & 4 \\
\hline E. faecalis & 100 & 95 & 100 & 100 & 100 & - & - & - & 16 \\
\hline E. coli & 82 & 60 & 68 & 78 & 62 & 100 & 93 & 95 & 2 \\
\hline
\end{tabular}

${ }^{a}$ Minimum inhibitory concentration (MIC) values represent the average of three readings with uncertainty about $5 \%{ }^{44}$ 
Table 4. Determination of the values of the solubility parameter $(\log \mathrm{P})$ and polar surface area (PSA) of the synthesized compounds ${ }^{45}$

\begin{tabular}{lcc}
\hline Compound & $\log \mathrm{P}$ & PSA \\
\hline $\mathbf{2 0}$ & 3.73 & 38.92 \\
$\mathbf{2 1}$ & 4.40 & 38.92 \\
$\mathbf{2 2}$ & 5.03 & 38.92 \\
$\mathbf{2 3}$ & 5.17 & 38.92 \\
$\mathbf{2 4}$ & 5.44 & 38.92 \\
$\mathbf{2 5}$ & 5.19 & 38.92 \\
$\mathbf{2 6}$ & 4.32 & 84.75 \\
$\mathbf{2 7}$ & 4.34 & 84.75 \\
$\mathbf{2 8}$ & 4.36 & 84.75 \\
$\mathbf{2 9}$ & 4.25 & 130.57 \\
$\mathbf{3 0}$ & 4.97 & 84.75 \\
$\mathbf{3 1}$ & 3.64 & 84.75 \\
$\mathbf{3 2}$ & 4.29 & 84.75 \\
$\mathbf{3 3}$ & 2.65 & 51.82 \\
$\mathbf{3 4}$ & 3.29 & 51.82 \\
$\mathbf{3 5}$ & 3.42 & 51.82 \\
$\mathbf{3 6}$ & 3.69 & 51.82 \\
$\mathbf{3 7}$ & 2.50 & 143.46 \\
$\mathbf{3 8}$ & 2.59 & 97.64 \\
$\mathbf{3 9}$ & 4.14 & 59.15 \\
\hline
\end{tabular}

$\log$ P: solubility parameter; PSA: polar surface area.

activities. The low $\log \mathrm{P}$ value indicates that this compound is less lipophilic and possibly this physicochemical feature affects its bioactivity, since low lipophilicity may be associated with a greater difficulty of diffusion through bacterial membranes. ${ }^{46}$

Compounds 29 and $\mathbf{3 7}$ have two nitro groups in their structure, however, they were inactive. This fact, at first glance, could indicate a contradiction, since the mononitrated compounds were active. However, on analyzing Table 4 it is apparent that the PSA values for 29 and $\mathbf{3 7}$ are considerably higher, suggesting a higher polarity in relation to the mononitrated ones. This result may again indicate a greater diffusion difficulty of these compounds through bacterial membranes, which could explain their lack of activity. ${ }^{46}$

The reason for the higher activity of the nitro compounds could be associated with the easy reduction of the nitro group, which is linked to its strong acceptance of electrons. Nitrated compounds can act via the enzymatic bioreduction mechanism, which results in the formation of free radicals with preferential toxicity to bacterial and parasitic cells. The nitro group is reduced by an electron transfer protein in the bacterium. The reduced nitro compound may cause deoxyribonucleic acid (DNA) spiral rupture. Mammalian cells remain unharmed as they lack the enzymes to reduce the nitro group. ${ }^{47}$

The transmembrane passageway of these molecules occurs by passive diffusion and increases as the free radicals from the bioreduction process destabilize the cell membrane. Thus, due to the increase in the intracellular concentration of nitro compounds, a greater number of free radicals can be generated and, consequently, greater damage is caused by oxidative stress ${ }^{48}$ (Scheme 3 ).

Biological activation through the bioreduction process of nitro compounds is a target to improve the biological activity of this class of compound. Thus, Rozenski et al. ${ }^{49}$ were able to relate the antibacterial action with the potential of reducing some nitrocompounds, proving that this bioactivity is due to the reduction of the nitro group. 49,50

The formation of free radicals from the bioreduction process of the nitro group can result in peroxidation of biological membranes and proteins, inhibition of enzymes and damage to DNA. One of the processes involved in the bioreduction of the nitro group in anaerobic and sometimes aerobic microorganisms is the interruption of the normal flow of electrons from the respiratory chain, which interferes with carbohydrate degradation, proton transposition and energy production. ${ }^{51}$

This mechanism could occur by inhibiting some enzymes belonging to the citric acid cycle involved in the formation of acetyl coenzyme A (CoA), CoA-SH from pyruvic acid, and in the subsequent process of cellular respiration. The enzymes of the pyruvate complex of microorganisms are responsible for the reduction of some nitrocompounds promoting the formation of free radicals $\left(\mathrm{Ar}-\mathrm{NO}_{2}{ }^{-}\right.$and $\left.\mathrm{OH}{ }^{*}\right)$ and the interruption of the physiological flow of electrons. The lethal event, however, is not the inhibition of respiration, but the formation of toxic radicals from oxidative stress. ${ }^{41}$

\section{Conclusions}

This work has demonstrated that a classical and easy-toexecute synthetic methodology can generate 1,2,4-oxadiazole derivatives active against certain strains of pathogenic bacteria. Some advantages of this synthetic method are the

$$
\mathrm{Ar}-\mathrm{NO}_{2} \stackrel{1 \mathrm{e}^{-}}{\rightleftharpoons} \mathrm{Ar}-\mathrm{NO}_{2} \cdot \stackrel{1 \mathrm{e}^{-}}{\longrightarrow} \mathrm{Ar}-\mathrm{NO} \stackrel{2 \mathrm{e}^{-}}{\rightleftharpoons} \mathrm{Ar}-\mathrm{NHOH} \stackrel{2 \mathrm{e}^{-}}{\longrightarrow} \mathrm{Ar}-\mathrm{NH}_{2}
$$

Scheme 3. Bioreduction of nitro compounds. 
availability of the starting materials and easy isolation of the compounds using silica column chromatography. The biological evaluation showed that the nature of the substituent groups, as well as their position on the aromatic ring of the compounds affected minimum inhibition concentration values. The results showed a possible pathway for the synthesis of new 1,2,4-oxadiazole bioactive derivatives.

\section{Supplementary Information}

Supplementary data are available free of charge at http://jbcs.sbq.org.br as PDF file.

\section{Acknowledgments}

We thank the agencies CAPES and CNPq for the financial support. The authors would like to thank Prof Dr Rafael Garrett (Laboratório de Apoio ao Desenvolvimento Tecnológico (LADETEC)) for the HRMS and Fundação Oswaldo Cruz for the NMR and IR spectra.

\section{References}

1. Neves, P. R.; Mamizuka, E. M.; Levy, C. E.; Lincopan, N.; J. Bras. Patol. Med. Lab. 2011, 47, 409.

2. Loureiro, R. J.; Roque, F.; Rodrigues, A. T.; Herdeiro, M. T.; Ramalheira, E.; Rev. Port. Saúde Pública 2016, 34, 77.

3. Ningaiah, S.; Bhadraiah, U. K.; Keshavamurthy, S.; Javarasetty, C.; Bioorg. Med. Chem. Lett. 2013, 23, 4532.

4. Pitasse-Santos, P.; Sueth-Santiago, V.; Lima, M. E. F.; J. Braz. Chem. Soc. 2018, 29, 435.

5. Tiemann, F.; Krüger, P.; Ber. Dtsch. Chem. Ges. 1884, 17, 1685.

6. Freitas, J. J. R.; Silva, E. E.; Regueira, J. L. L. F.; de Andrade, S. A.; Calvalcante, P. M. M.; Oliveira, R. N.; Freitas Filho, J. R.; Rev. Virtual Quim. 2012, 4, 670.

7. Yatam, S.; Gundla, R.; Jadav, S. S.; Pedavenkatagari, N.; Chimakurthy, J.; Rani, N.; Kedam, T.; J. Mol. Struct. 2018, 1159, 193.

8. Zhang, P.; Chen, J. H.; Dong, X.; Tang, M. T.; Gao, L. Y.; Zhao, G. S.; Yu, L. G.; Guo, X. L.; Biomed. Pharmacother. 2013, 67, 58.

9. Bartolozzi, A.; Abeywardane, A.; Bosanac, T.; Broadwater, J.; Chen, Z.; Hutzler, J.; Huber, J.; Nemoto, P.; Olague, A.; Riether, D.; Simpson, T.; Takahashi, H.; Wu, L.; Zhang, Y.; Zindell, R.; Bioorg. Med. Chem. Lett. 2017, 27, 4652.

10. Zahanich, I.; Kondratov, I.; Naumchyk, V.; Kheylik, Y.; Platonov, M.; Zozulya, S.; Krasavin, M.; Bioorg. Med. Chem. Lett. 2015, 25, 3105.

11. Maftei, C. V.; Fodor, E.; Jones, P. G.; Daniliuc, C. G.; Franz, M. H.; Kelter, G.; Fiebig, H. H.; Tamm, M.; Neda, I.; Tetrahedron 2016, 72, 1185 .
12. Gobec, M.; Tomasic, T.; Markovic, T.; Mlinaric-Rascan, I.; Dolenc, M. S.; Jakopin, Z.; Chem.-Biol. Interact. 2015, 240, 200.

13. Karad, S. C.; Purohit, V. B.; Thummar, R. P.; Vaghasiya, B. K.; Kamani, R. D.; Thakor, P.; Thakkar, V. R.; Thakkar, S. S.; Ray, A.; Raval, D. K.; Eur. J. Med. Chem. 2017, 126, 894.

14. Parra, M.; Hidalgo, P.; Carrasco, E.; Barberá, J.; Silvino, L.; Liq. Cryst. 2006, 33, 875.

15. Tomi, I. H. R.; J. Saudi Chem. Soc. 2012, 16, 153.

16. Guo, J.; Hua, R.; Sui, Y.; Cao, J.; Tetrahedron Lett. 2014, 55, 1557.

17. Pace, A.; Pierro, P.; Org. Biomol. Chem. 2009, 7, 4337.

18. Kivrac, A.; Zora, M.; Tetrahedron 2014, 70, 817.

19. Srivastava, R. M.; Quim. Nova 1995, 18, 303.

20. Kundu, M.; Singh, J.; Singh, B.; Ghosh, T.; Maiti, B. C.; Maiti, T. K.; Indian J. Chem. 2012, 51B, 493.

21. Ostrosky, E. A.; Mizumoto, M. K.; Lima, M. E. L.; Kaneko, T. M.; Nishikawa, S. O.; Freitas, B. R.; Rev. Bras. Farmacogn. 2008, 18, 301.

22. Piccionello, A. P.; Musumeci, R.; Cocuzza, C.; Fortuna, C. G.; Guarcello, A.; Pierro, P.; Pace, A.; Eur. J. Med. Chem. 2012, 50,441 .

23. Cottrell, D. M.; Capers, J.; Salem, M. M.; Deluca-Fradley, K.; Croft, S. L.; Werbovetz, K. A.; Bioorg. Med. Chem. 2004, 12, 2815.

24. Rakesh, D.; Sun, R. B.; Tangallapally, L. P.; Lee, R. E.; Eur. J. Med. Chem. 2009, 44, 460.

25. Huguet, F.; Melet, A.; Sousa, R. A.; Lieutaud, A.; ChemMedChem 2012, 7, 1020.

26. Leemans, E.; Mahasenan, K. V.; Kumarasiri, M.; Spink, E.; Ding, D.; O’Daniel, P. I.; Boudreau, M. A.; Lastochkin, E.; Testero, S. A.; Yamaguchi, T.; Lee, M.; Hesek, D.; Fisher, J. F.; Chang, M.; Mobashery, S.; Bioorg. Med. Chem. Lett. 2016, 26, 1011.

27. Araújo, C. R. M.; Leite Filho, C. A.; Santos, V. L. A.; Maia, G. L. A.; Gonsalves, A. A.; Quim. Nova 2015, 38, 868.

28. Ciusa, R.; Parisi, E.; Gazz. Chim. Ital. 1923, 53, 663.

29. Huisgen, R.; Mack, W.; Anneser, E.; Tetrahedron Lett. 1961, 587.

30. Zhang, H. Z.; Kasibhatla, S.; Kuemmerle, J.; Kemnitzer, W.; Ollis-Mason, K.; Qiu, L.; Crogan-Grundy, C.; Tseng, B.; Drewe, J.; Cai, S. X.; J. Med. Chem. 2005, 48, 5215.

31. Rostamizadeh, S.; Ghaieni, H. R.; Aryan, H. R.; Amani, A. M.; Tetrahedron 2010, 66, 494.

32. Haugwitz, R. D.; Martinez, A. J.; Venslavsky, J.; Angel, R. G.; Maurer, B. V.; Jacobs, G. A.; Narayanan, V. L.; Cruthers, L. R.; Szanto, J.; J. Med. Chem. 1985, 28, 1234.

33. Dohi, T.; Suda, M.; Morikawa, S.; Kitamura, T.; Ishikawa, T.; Jpn. Kokai Tokkyo Koho 20072973072007.

34. Leandri, G.; Palloti, M.; Ann. Chim. 1957, 47, 376.

35. Clarke, K.; J. Chem. Soc. 1954, 4251. 
36. Harsanyi, K.; Reiter, J.; Korbonits, D.; Gonczi, C.; Takacs, K.; Bako, E.; Leszkovszky, G.; Tardos, L.; Vertessy, C.; Hungarian patent 1569761970.

37. Dahl, B. H.; Peters, D.; Olsen, G. M.; Timmermann, D. B.; Joergensen, S.; WO pat. 20061144002006.

38. Bulgarevich, S. B.; Yusman, T. A.; Ryabukhina, O. Y.; Dorokhova, N. I.; Ryabukhin, Y. I.; Dorofeenko, G. N.; Osipov, O. A.; Zh. Obshch. Khim. 1981, 51, 1418.

39. Ding, D.; Boudreau, M. A.; Leemans, E.; Spink, E.; Yamaguchi, T.; Testero, S. A.; O’Daniel, P. I.; Lastochkin, E.; Chang, M.; Mobashery, S.; Bioorg. Med. Chem. Lett. 2015, 25, 4854.

40. Barreiro, E. J.; Fraga, C. A. M.; Química Medicinal: as Bases Moleculares da Ação dos Fármacos, $1^{\mathrm{a}}$ ed.; ArtMed: Porto Alegre, Brasil, 2001.

41. Paula, F. R.; Serrano, S. H. P.; Tavares, L. C.; Quim. Nova 2009, 32, 1013.

42. Moreth, M.; Ornelas, D.; Gomes, C. R. B.; De Sousa, M. V. N.; Rev. Virtual Quim. 2010, 2, 105.

43. Sahin, G.; Palaska, E.; Ekizoglu, M.; Ozalp, M.; Farmaco 2002, 57,539 .
44. Steward, C. D.; Stocker, S. A.; Swenson, J. M.; O’Hara, C. M.; Edwards, J. R.; Gaynes, R. P.; McGowan Jr., J. E.; Tenover, F. C.; J. Clin. Microbiol. 1999, 37, 544.

45. http://www.molinspiration.com/cgi-bin/properties, accessed in June 2018.

46. Wang, C.-H.; Xie, X.-R.; Liu, W.-S.; Hou, G.-G.; Sun, J.-F.; Zhao, F.; Cong, W.; Li, H.-J.; Xin, W.-Y.; Chem. Biol. Drug Des. 2017, 90, 943.

47. Eley, B. M.; Soory, M.; Manson, J. D.; Periodontia, 6 ${ }^{\mathrm{a}}$ ed.; Elsevier: Rio de Janeiro, Brasil, 2012.

48. Viodé, C.; Bettache, N.; Cenas, N.; Krauth-Siegel, R. L.; Chauviére, G.; Bakalara, N.; Périé, J.; Biochem. Pharmacol. 1998, 57, 549.

49. Rozenski, J.; De Ranter, C. J.; Verplanken, H.; Quant. Struct.Act. Relat. 1995, 14, 134.

50. Padilla, M. N.; Mata-Pérez, C.; Melguizo, M.; Barroso, J. B.; Nitric Oxide 2017, 68, 14.

51. Tocher, J. H.; Gen. Pharmacol. 1997, 28, 485.

Submitted: April 5, 2018

Published online: June 20, 2018 